\title{
Improvement of growth and bacoside production in Bacopa monnieri through induced autotetraploidy with colchicine
}

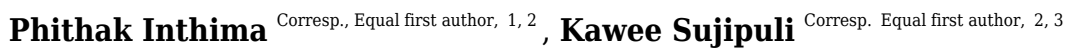 \\ ${ }^{1}$ Plant Tissue Culture Research Unit, Department of Biology, Faculty of Science, Naresuan University, Phitsanulok, Thailand \\ 2 Center of Agricultural Biotechnology, Naresuan University, Phitsanulok, Thailand \\ 3 Department of Agricultural Science, Faculty of Agriculture Natural Resources and Environment, Naresuan University, Phitsanulok, Thailand \\ Corresponding Authors: Phithak Inthima, Kawee Sujipuli \\ Email address: phithaki@nu.ac.th, kawees@nu.ac.th
}

Bacopa monnieri is a medicinal herb that is increasing in demand in Thailand. However, the lack of high-bacoside cultivars has limited pharmaceutical utilization and production. Here, chromosome doubling in $B$. monnieri was attempt to improve biomass and bacoside content in its seedling. Nodal segments were treated with colchicine $(0,0.025,0.05,0.075$, 0.1 , and $0.5 \% \mathrm{w} / \mathrm{v}$ ) for 24 or 48 hours before transferring to multiple shoot induction medium ( $1 / 2 \mathrm{MS}$ medium supplemented with $0.2 \mathrm{mg} \mathrm{L}^{-1} \mathrm{BAP}$ ). Of 326 tested clones, 18 and 84 were mixoploids and autotetraploids, respectively. The highest autotetraploid-induction percentage (14.6\%) was found after treated with $0.5 \%(\mathrm{w} / \mathrm{v})$ colchicine, and 48 hours exposure. From 28 selected autotetraploid clones, 21 and 13 have significantly higher fresh and dry weight compared to the diploid clone, respectively. The maximum fresh and dry weight of autotetraploid plants was 2.8 and 2.0-time higher than diploid plants, respectively. Moreover, the maximum total bacoside content $\left(1.55 \mathrm{mg} \mathrm{plant}^{-1}\right)$ was obtained from an autotetraploid plant, which was 2.3-fold higher than the level in diploid plants. These novel autotetraploids have the potential to be developed as resources for value-added improvements in the medicinal and pharmaceutical industries. 


\section{Improvement of growth and bacoside production in}

3 Bacopa monnieri through induced autotetraploidy 4 with colchicine

\section{Phithak Inthima ${ }^{1,2}$, Kawee Sujipuli ${ }^{2,3}$}

${ }^{1}$ Plant Tissue Culture Research Unit, Department of Biology, Faculty of Science, Naresuan University, Phitsanulok, Thailand

${ }^{2}$ Center of Agricultural Biotechnology, Naresuan University, Phitsanulok, Thailand

${ }^{3}$ Department of Agricultural Science, Faculty of Agriculture Natural Resources and Environment, Naresuan University, Phitsanulok, Thailand

The authors contributed equally to this work.

Corresponding Author:

Phithak Inthima ${ }^{1,2}$

Plant Tissue Culture Research Unit, Department of Biology, Faculty of Science, Naresuan University, Phitsanulok, Thailand

Email address: phithaki@nu.ac.th

Kawee Sujipuli ${ }^{2,3}$

Department of Agricultural Science, Faculty of Agriculture Natural Resources and Environment, Naresuan University, Phitsanulok 65000, Thailand

Email address: kawees@nu.ac.th

\section{Abstract}

Bacopa monnieri is a medicinal herb that is increasing in demand in Thailand. However, the lack of high-bacoside cultivars has limited pharmaceutical utilization and production. Here, chromosome doubling in $B$. monnieri was attempted to improve biomass and bacoside content in its seedling. Nodal segments were treated with colchicine $(0,0.025,0.05,0.075,0.1$, and $0.5 \%$ $\mathrm{w} / \mathrm{v})$ for 24 or 48 hours before transferring to multiple shoot induction medium ( $1 / 2 \mathrm{MS}$ medium supplemented with $0.2 \mathrm{mg} \mathrm{L}^{-1}$ BAP). Of 326 tested clones, 18 and 84 were mixoploids and autotetraploids, respectively. The highest autotetraploid-induction percentage (14.6\%) was found after treated with $0.5 \%(\mathrm{w} / \mathrm{v})$ colchicine, and 48 hours exposure. From 28 selected autotetraploid clones, 21 and 13 have significantly higher fresh and dry weight compared to the diploid clone, 
respectively. The maximum fresh and dry weight of autotetraploid plants was 2.8 and 2.0-time higher than diploid plants, respectively. Moreover, the maximum total bacoside content $(1.55 \mathrm{mg}$ plant $^{-1}$ ) was obtained from an autotetraploid plant, which was 2.3 -fold higher than the level in diploid plants. These novel autotetraploids have the potential to be developed as resources for value-added improvements in the medicinal and pharmaceutical industries.

\section{Introduction}

Bacopa monnieri (commonly known as waterhyssop or brahmi in Ayurvedic medicine) is a small succulent herb that grows in marshy and moist tropical regions (Tripathi et al., 2012). It has been extensively utilized as a traditional Ayurvedic medicine to enhance memory and brain rejuvenation, promote longevity and improve intellectual functions (Gubbannavar et al., 2012). Various pharmacological effects of brahmi have been reported including anti-parkinson's (Jansen et al., 2014), antidepressant (Rauf et al., 2014), anti-anxiety (Pandareesh et al., 2014), and as an Alzheimer's disease treatment (Uabundit et al., 2010). The bioactive compounds of brahmi are mainly associated with triterpenoid saponins as complex mixtures (Deepak et al., 2005). Of these, bacoside A is the core active compound which acts as a memory booster (Ramasamy et al., 2015). Biosynthetic pathway of triterpenoid saponins, like sterols, had been hypothesized through both the mevalonic acid (MVA) and the methylerythritol phosphate (MEP) pathways (Augustin et al., 2011), resulting in the formation of intermediate substance as the farnesyl pyrophosphate $(F P P)$ by two enzyme actives of dimethylallyl diphosphate $(D M A P P)$, and geranyl pyrophosphate (GPP) (Acharya et al., 2009). This substance converts into a $\mathrm{C}_{30}$ molecule squalene by squalene synthase (SQS), and its molecule subsequently cyclizes into triterpene skeletons by 2, 3-oxidosqualene (OSCs) (Niua et al., 2014). Finally, their skeletons are catalyzed by cytochrome P450-dependent monooxygenases (CYP450) and glycosyltransferase (GT) to produce triterpenoid saponins (Abbassi et al., 2015). Since the triterpenoid saponin pathway involved with many genes, so the improvement of a new variety for increasing saponin by pollination breeding is time consuming and extremely difficult (Samaddar et al., 2012).

Many products containing brahmi are widely available today. To satisfy the high commercial demand, 1,000 tons of raw plant material were used by herbal industries in 2011 (Muthiah et al., 2013), with most of this collected from the natural resources (Tewari, 2000) and this led to the rapid depletion of wild natural plants. However, cultivation of brahmi is restricted to certain agroclimatic conditions in wetlands and muddy shores, and natural regeneration through seeds or cuttings is slow and requires good irrigation facilities. Moreover, improvement of new varieties of brahmi by conventional breeding is time consuming and difficult since the plant has a small flower and a high number of chromosomes, $2 \mathrm{n}=2 x=64$ (Samaddar et al., 2012). Therefore, new techniques have been developed to improve brahmi production. One of the most popular techniques is elicitation with elicitors (physical agent, biological or chemical substances) 
79

80

81

82

83

84

85

86

87

88

89

90

91

92

93

94

95

96

97

98

99

100

101

102

103

104

105

106

107

108

109

110

111

112

113

114

115

116

117

treatments (Sharma et al., 2013) to increase bacoside content. However, since there are few reports concerning biosynthetic pathways in brahmi, the effects and functions of elicitation are difficult to predict. One technique to solve this limitation involves creating new sustainable varieties of brahmi through polyploidization using colchicine treatment because it is a rapid, cost-effective, efficient and safe method (Sattler et al., 2016). Moreover, previous studies have reported that tetraploid plants exhibit increased heterosis (hybrid vigor) such as increased oil content in Ocimum basilicum (Omidbaigi et al., 2010), wider and thicker leaves in Fagopyrum tataricum (Wang et al., 2017), and increased root size in Echinacea purpurea (Chen et al., 2016). Previous studies have shown that the brahmi polyploids have been improved by enlarging the flower size (Escandón et al., 2006) and the shoot (Sangeetha et al., 2011), this is possible that the biomass and bacoside yield could be improved by polyploidization. In this study, chromosome doubling in B. monnieri was attempted to improve biomass and bacoside content in its seedling. The results may be beneficial for further genetic improvements to increase the medicinal value of brahmi and raw drug production.

\section{Materials \& Methods}

\section{Plant material and colchicine treatment}

Nodal segments ( $1 \mathrm{~cm}$ in length) of diploid B. monnieri were cut from one month in vitro culture plantlets. These segments were treated with $1 / 2$ MS (Murashige \& Skoog, 1962) liquid medium supplemented with one of six different colchicine concentrations $(0.025,0.05,0.075,0.1$ or $0.5 \%$ $\mathrm{w} / \mathrm{v}$ ) in parallel with nodal segments in $1 / 2 \mathrm{MS}$ only as the control. All samples were incubated with shaking at $100 \mathrm{rpm}$ for 24 or 48 hours under the condition of $25 \pm 2{ }^{\circ} \mathrm{C}$ in a 10 -hour photoperiod with the light intensity of $20 \mu \mathrm{mol} \mathrm{m} \mathrm{m}^{-2} \mathrm{~s}^{-1}$ provided by warm white LED lamps. After treatment, all colchicine treated explants were rinsed with sterilized distilled water five times and then transferred to solidified $1 / 2 \mathrm{MS}$ medium supplemented with $0.2 \mathrm{mg} \mathrm{L}^{-1} 6$ Benzylaminopurine (BAP, Sharma et al., 2010). The cultures were kept for 8 weeks under the same standard condition as mentioned above, but without shaking.

\section{In vitro regenerant screening and flow cytometry analysis}

Shoots of eight-week-old treated regenerants were excised and transferred to fresh solidified $1 / 2 \mathrm{MS}$ medium without hormone, and cultured under the same standard conditions for 6 weeks. The putative polyploid plants were screened using the criteria of bigger and thicker leaves and stems, as compared to diploid plantlets (Escandón et al., 2006). These plants were further confirmed for polyploidy level by a flow cytometry assay. A leaf sample (100 mg) was chopped with a razor blade in a petri dish containing $1 \mathrm{~mL}$ nuclei extraction buffer (200 mM Tris, $4 \mathrm{mM}$ $\mathrm{MgCl}_{2} .6 \mathrm{H}_{2} \mathrm{O}, 0.5 \%(\mathrm{v} / \mathrm{v})$ Triton X-100, $\mathrm{pH} 7.5$ ) according to the method of Pfosser et al. (1995). The nuclei suspension was filtered through a $40 \mu \mathrm{m}$ nylon net (Merck Millipore Ltd., Germany) and stained using the Muse ${ }^{\mathrm{TM}}$ Cell Cycle Kit (Merck KGaA, Germany). The polyploidy level 
118 was analyzed on a Guava ${ }^{\circledR}$ easyCyte Flow Cytometer with InCyte ${ }^{\mathrm{TM}}$ software version 2.7 (Merck

119 KGaA, Germany).

120

121

122

Morphological observations in autotetraploid plants

123

The autotetraploid clones were in vitro proliferated on $1 / 2 \mathrm{MS}$ for 8 weeks and the plantlets with

124 the same height were transplanted into pots containing $1 / 2$ Hoagland solution (HS, Hoagland \& Arnon, 1950) and kept under greenhouse condition for 30 days. At least five plants per clone were grown and observed for biomass, height, leaf thickness, stem diameter and additionally

126 quantifies for bacoside content. For measurement of leaf thickness and stem diameter, the $5^{\text {th }}$ leaf and internode were cross section with a razor blade. The samples were observed and measured under light microscope. The measurements were undertaken with 5 measuring points per leaf or stem of five individual plants.

130

\section{Quantification of bacoside content}

132

133

Bacoside content was quantified using the modified method of Bansal et al. (2016). Briefly, aerial parts of 30-day-old hydroponically grown plants were dried at $40{ }^{\circ} \mathrm{C}$ for 2 days and then ground to a fine powder. The powder $(0.1 \mathrm{~g})$ was then extracted with $3 \mathrm{~mL}$ methanol by incubated at room temperature for 1 hour, sonicated for 15 minutes and then incubated in the dark at $4{ }^{\circ} \mathrm{C}$ for 5 minutes. After centrifugation at 8,000 rpm for 5 minutes, the supernatant was filtered through a $0.45-\mu \mathrm{m}$ nylon filter (Tianjin Fuji Science and Technology Co., Ltd., China). Bacoside content in the filtered extracts was analyzed on a HPLC system (Shimadzu, Japan) equipped with Purospher ${ }^{\circledR}$ STAR-RP-18 endcapped (5 $\left.\mu \mathrm{m}\right)$ LiChroCART ${ }^{\circledR}$ 250-4.6 column (Merck, Germany). The chromatographic condition was as follows: (i) the mobile phase was $0.2 \%(\mathrm{v} / \mathrm{v})$ aqueous phosphoric acid, $\mathrm{pH} 0.3$ and acetonitrile $(65: 35 \mathrm{v} / \mathrm{v})$, (ii) the flow rate was 1

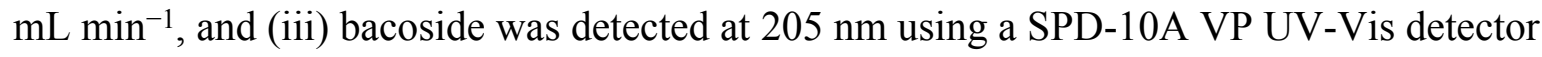
(Shimadzu, Japan). The bacoside content in the plant extracts was calculated by a linearity

\section{Statistical analysis}

The experiment was conducted using a complete randomized design. The differences in fresh weight, dry weight and height of autotetraploid and diploid plants were compared by $t$-test. Other

150 data were analyzed using one-way analysis of variance (ANOVA) and Duncan's multiple range test (DMRT).

152

\section{Results and Discussion}

\section{Effect of colchicine on growth and phenotypic variation of regenerated brahmi}

155

Eight weeks after transfer of the colchicine-treated nodal segments to new $1 / 2 \mathrm{MS}$, the highest 
158 than the control and other treatments (Fig. 1A). Shoot multiplication and shoot length

159

160

161

162

163

164

165

166

167

168

169

170

171

172

173

174

175

176

177

178

179

180

181

182

183

184

185

186

187

188

189

190

191

192

193

194

195

196

197

significantly decreased with increasing concentrations and exposure times of colchicine as compared to untreated explants (Table 1, Fig. 1A). Increasing concentrations and exposure times of colchicine have been shown to inhibit growth and shoot regeneration of explants (Javadian et al., 2017; Wang et al., 2017). Moreover, higher concentrations of colchicine with longer exposure times can be toxic to plants leading to tissue abnormalities (Megbo, 2010) and dead (Mondin et al., 2018)

Some regenerants of colchicine-treated explants showed distinct morphological feature changes in leaf and stem such as albinoism (Fig. 1B), a spiral stem (Fig. 1C), variegated leaves (Fig. 1D), whorls of three (Fig. 1E) and four (Fig. 1F) leaves, and a fasciated stem (Fig. 1G). These results indicated that colchicine treatment induced phenotypic changes in the regenerated brahmi.

Several published studies have reported that colchicine-induced wide morphological variations such as leaf arrangement and size in Platycodon grandiflorus (Wu et al., 2011) and Hebe (Gallone et al., 2014), stomatal size in Pogostemon cablin (Yan et al., 2016) and cassava (Mondin et al., 2018), and leaf, flower, and seed size in Fagopyrum tataricum (Wang et al., 2017).

\section{Flow cytometry analysis for determining polyploidy level in colchicine-treated plantlets} From a total of 1,262 regenerants, 326 putative autotetraploid clones were selected based on criteria of bigger and thicker leaves and stems as compared to diploid plantlets. Polyploidy level was analyzed by flow cytometry. The DNA content peak of a diploid control plant $(2 x ; 2 n=64)$ was set at channel 100 (Fig. 2A) and the peak of an autotetraploid plant $(4 x ; 2 n=128)$ was measured at channel 200, which was twofold intensity compared to that of diploid plantlets (Fig. 2B). Of 326 clones tested, only 18 and 84 clones were mixoploid (a plant composed of both $2 x$ and $4 x$ cell, Fig. 2C) and autotetraploid, respectively (Table 1). Among the twelve colchicine treatment combinations, the mixoploid- and autotetraploid-induction efficiencies (\%) ranged between $0.0-5.1 \%$ and $0-14.6 \%$, respectively (Table 1 ). The highest autotetraploid-induction efficiency $(14.6 \%)$ was found in the combination of treated with $0.5 \%(\mathrm{w} / \mathrm{v})$ colchicine and exposure for 48 hours (Table 1). Moreover, the highest mixoploid induction (5.1\%) was found after treatment with $0.1 \%(\mathrm{w} / \mathrm{v})$ colchicine and exposure of 48 hours (Table 1). In contrast, treatment of explants with $0.025 \%$ colchicine for 24 hours did not induce autotetraploid in any regenerated plantlets (Table 1). In this study, nodal segments of brahmi treated with $0.5 \%$ colchicine solution for 48 hours was the most useful condition to generate the highest number of autotetraploid plantlets. Because colchicine plays an important role in inhibiting microfilament and microtubule formation and disturbs mitosis at the anaphase stage, chromosomes do not migrate to the opposite ends of the cell during cell division, resulting in chromosome doubling in the cell (Pour et al., 2012). Furthermore, a recent study reported that colchicine affected numerous genes related to the spindle, the chromosomal kinetochore, vesicles, cellulose and the processes of cytoplasm movement, chromatid segregation, as well as membrane and cell wall

Peer) reviewing PDF | (2019:05:37845:2:0:NEW 21 Sep 2019) 
198

199

200

201

202

203

204

205

206

207

208

209

210

211

212

213

214

215

216

217

218

219

220

221

222

223

224

225

226

227

228

229

230

231

232

233

234

235

236

237

development (Zhou et al., 2017). For this reason, colchicine is a highly potent antimitotic agent which has been successfully used for inducing polyploidy in many plant species (Pour et al., 2012; Wang et al., 2017; Mondin et al., 2018).

\section{Agricultural characters in autotetraploid plantlets}

Of the 84 autotetraploids, 28 clones were selected (based on in vitro growth performances) and transplanted into $1 / 2 \mathrm{HS}$ under greenhouse conditions for 30 days. The results showed that 21 and 13 examined autotetraploids clones had significantly higher fresh and dry weight compared to diploid clone, respectively (Figs. 3A and 3B). The highest fresh $\left(1.50 \mathrm{~g} \mathrm{plant}^{-1}\right)$ and dry $(0.072 \mathrm{~g}$ plant $^{-1}$ ) weight was found in autotetraploid-plant clone $4 x-103$ (Fig. 4A), which was around 2.8 and 2.0-time higher than diploid plants, respectively (Figs. 3A and 3B). This was probably due to the autotetraploid having thicker leaves (Figs. 4B and 4D) and larger stem diameter (Figs. 4C and 4E) than its diploid progenitor. In contrast, shoot height in 6 autotetraploid clones slightly increased $(16.0$ to $18.8 \mathrm{~cm})$ more than diploid plant $(14.2 \mathrm{~cm})$, and almost half $(16$ of 28$)$ of the tetraploid clones were not significantly different from the diploid plant controls (Fig. 3C). The results clearly showed that most of the selected autotetraploid plants had significantly greater fresh weight, dry weight, and shoot height than diploid plants. The reasons of this were possible that colchicine-side and double-gene-dosage effects, that might either increase or decrease biomass and metabolite production of polyploids (Javadian et al., 2017; Salma et al., 2018). In some cases, polyploids were much more effective in superior vegetative-tissue shapes and sizes than diploids, which may be the reason for an increase in biomass yields (Wang et al., 2017). Another reason for this was that colchicine might have induced morphological variations such as leaf and stem thickness, causing enhanced fresh weight and dry weight (Niu et al., 2016). Moreover, chromosome doubling might have induced the differential gene expression between diploid and synthesized tetraploid, therefore affecting the various phenotypic traits (Liqin et al., 2019). The previous study has shown differences in gene expression between diploid and triploid of Populus, involved in carbohydrate and lipid metabolism in triploid, reflected a more significant increase in carbon metabolism and utilization efficiency than diploids, which may be responsible for the fast-growing trait observed in triploids (Cheng et al., 2015). The organ sizes (plant height, leaf area, and petiole length) were significantly superior in polyploids than diploids Populus (Liqin et al., 2019), since polyploids might be up-regulated the growth-regulating factor (GRF) gene family, played vital roles in the control of plant growth development (Wu et al., 2014).

\section{Accumulation of bacoside content in autotetraploid explant}

Of the 28 autotetraploid clones, 14 representatives were selected using the criteria of higher fresh weight and/or dry weight than diploid plants. Total bacoside content of 14 representatives was quantified using HPLC as shown in Table 2. Only one autotetraploid clone (4x-59, Fig. 4A) had a significantly $(p \leq 0.05)$ higher total bacoside contents than the diploid clones. However, two autotetraploid clones ( $4 x-59$ and $4 x-103)$ had maximum amounts of bacoside at 1.55 and $1.10 \mathrm{mg}$ 
238 plant $^{-1}$ respectively, as compared to diploid clone $\left(0.68 \mathrm{mg} \mathrm{plant}^{-1}\right)$ and significantly $(p \leq 0.05)$

239 higher than diploid clone by 2.3 and 1.6 folds, respectively. This suggested that their polyploidy

240 may be associated with improving secondary metabolite content in brahmi.

241 Since the biosynthetic pathways of secondary metabolites involve many steps and require several

242 enzymes, it was hypothesized that doubling chromosome number in autopolyploid plants may

243 increase the number of gene copies. This may lead to increased enzymatic synthesis and

244 metabolic activity, which may provide additional substrates for enhancing secondary plant

245 metabolites (Salma et al., 2017). Previous publications have reported more abundant proteins

246 related to the biosynthesis of secondary metabolites in autotetraploid than diploid Paulownia

247 australis (Wang et al., 2017). Similarly, the polyploidy-mediated change in phenotypic traits

248 may appear as an effect of secondary metabolite biosynthesis. For example, enhancement of the

249 leaf area and leaf thickness in autotetraploid Stevia rebaudiana were positively affected

250 glycoside biosynthesis as a result of increased photosynthesis (Hegde et al., 2015). Similarly, 251 polyploidization enhances the content of triterpenoid in Jatropha curcas (Niu et al., 2016),

252 patchouli alcohol in Pogostemon cablin (Yan et al., 2016), and flavonoid in Fagopyrum

253 tataricum (Wang et al., 2017) as compared to diploid plants. Additionally, it has been reported

254 that the level of artemisinin in tetraploids of Artemisia annua was higher than diploid due to a

255 significant increase of artemisinin metabolite-specific genes (Lin et al., 2011). Likewise,

256 podophyllotoxin production in tetraploid Linum album was increased over diploid due to higher

257 expression of genes related to its biosynthesis (Javadian et al., 2017). So, the enhancement of

258 secondary metabolite production of tetraploid compared to diploid might be that the expression

259 of crucial biosynthesis genes in tetraploid was increased.

260

261

262 Conclusions

263 This present study demonstrated that colchicine-mediated technique was successfully used in in

264 vitro induction of autotetraploidy in Bacopa monnieri. Most autotetraploid plants were superior

265 in agricultural characteristics (such as fresh weight, dry weight and total bacoside content) than

266 the original parental diploid plants. This suggests that the novel autopolyploids developed here

267 may be of use in improving the quality and quantity of medicinal plant raw material, to the

268 benefit of the medical and pharmaceutical industries.

269

270

271 Acknowledgements

272 The authors are appreciative for the comments and English language editing of Prof. Duncan

273 Richard Smith, Ph.D., Institute of Molecular Biosciences, Mahidol University, Thailand.

274

275

276 References 
277

278

279

280

281

282

283

284

285

286

287

288

289

290

291

292

293

294

295

296

297

298

299

300

301

302

303

304

305

306

307

308

309

310

311

312

313

314

315

Abbassi SJ, Vishwakarma RK, Patel P, Kumari U, Khan BM. 2015. Bacopa monniera recombinant mevalonate diphosphate decarboxylase: Biochemical characterization. International Journal of Biological Macromolecules 79:661-668

Acharya DAC, Mitaine-Offer AC, Kaushik N, Miyamoto T, Paululat T, Mirjolet JF, Duchamp O, Lacaille-Dubois MA. 2009. Cytotoxic spirostane-type saponins from the roots of Chloro phytum borivilianum. Journal of Natural Products 72:177-181.

Augustin JM, Kuzina V, Andersen SB, Bak S. 2011. Molecular activities, biosynthesis and evolution of triterpenoid saponins. Phytochemistry 72: 435-457

Bansal M, Reddy MS, Kumar A. 2016. Seasonal variations in harvest index and bacoside A contents amongst accessions of Bacopa monnieri (L.) Wettst. collected from wild populations. Physiology and Molecular Biology of Plants 22:407-413

Chen R, Yang Y, Wu H. 2016. A comparative study on rooting of in vitro regenerated shoots in haploid, diploid and tetraploid purple coneflower (Echinacea purpurea L.). Biotechnology \& Biotechnological Equipment 30:44-48

Cheng S, Yang J, Liao T, Zhu X, Suo Y, Zhang P, Wang J, Kang X. 2015. Transcriptomic changes following synthesis of a Populus full-sib diploid and allotriploid population with different heterozygosities driven by three types of $2 \mathrm{n}$ female gamete. Plant Molecular Biology 89:493-510

Deepak M, Sangli GK, Arun PC, Amit A. 2005. Quantitative determination of the major saponin mixture bacoside A in Bacopa monnieri by HPLC. Phytochemical Analysis 16:24-29

Escandón AS, Hagiwara JC, Alderete LM. 2006. A new variety of Bacopa monnieri obtained by in vitro polyploidization. Electronic Journal of Biotechnology 9:181-186

Gallone A, Hunter A, Douglas GC. 2014. Polyploid induction in vitro using colchicine and oryzalin on Hebe 'Oratia Beauty': Production and characterization of the vegetative traits.

Scientia Horticulturae 179:59-66

Gubbannavar JS, Harisha CR, Chandola HM. 2012. A comparative study of roots of Bacopa monnieri (L.) Pennel and Bacopa floribunda (R.Br.) wettst. International Journal of

Pharmacognosy and Phytochemical Research 4:8-11

Peer] reviewing PDF | (2019:05:37845:2:0:NEW 21 Sep 2019) 
316 Hegde SN, Rameshsing CN, Vasundhara M. 2015. Characterization of Stevia rebaudiana

317 Bertoni polyploids for growth and quality. Medicinal Plants 7:188-195

318

319 Hoagland DR, Arnon DI. 1950. The water-culture method for growing plants without soil,

320 Circular 347, California Agricultural Experiment Station, University of California, California

321

322

Jansen R, Brogan B, Whitworth A Okello E. 2014. Effects of five ayurvedic herbs on locomotor

323 behaviour in a Drosophila melanogaster parkinson's disease model. Phytotherapy Research

324 28:1789-1795

325

326

Javadian N, Karimzadeh G, Sharifi M, Moieni A, Behmanesh M. 2017. In vitro polyploidy

327 induction, changes in morphology, podophyllotoxin biosynthesis, and expression of the related

328 genes in Linum album (Linaceae). Planta 245:1165-1178

329

330

Javadian N, Karimzadeh G, Sharifi M, Moieni A, Behmanesh M. 2017. In vitro polyploidy

331 induction: changes in morphology, podophyllotoxin biosynthesis, and expression of the related

332

333

334 genes in Linum album (Linaceae). Planta 245:1165-1178

335

Lin X, Zhou Y, Zhang J, Lu X, Zhang F, Shen Q, Wu S, Chen Y, Wang T, Tang K. 2011. Enhancement of artemisinin content in tetraploid Artemisia annua plants by modulating the

336 expression of genes in artemisinin biosynthetic pathway. Biotechnology and Applied

337 Biochemistry 58:50-57

338

339

Liqin G, Jianguo Z, Xiaoxia L, Guodong R. 2019. Polyploidy-related differential gene

340 expression between diploid and synthesized allotriploid and allotetraploid hybrids of Populus.

341 Molecular Breeding 39:69

342

343

Megbo BC. 2010. The physiological effects of colchicine in Okra, Hibiscus esculentus L, plant

344

345

346 growth and development. International Journal of Scientific \& Engineering Research 1:29-33

Mondin M, de Mello e Silva PAKX, Latado RR, Mourão Filho FAA. 2018. In vitro induction and regeneration of tetraploids and mixoploids of two cassava cultivars. Crop Breeding and 349 Applied Biotechnology 18:176-183

Murashige T, Skoog F. 1962. A revised medium for rapid growth and bioassays with tobacco tissue cultures. Physiologia Plantarum 15:437-497

352 in vitro tissues of Bacopa monnieri after 6 months of storage by using ISSR and RAPD markers. 
356

357

358

359

360

361

362

363

364

365

366

367

368

369

370

371

372

373

374

375

376

377

378

379

380

381

382

383

384

385

386

387

388

389

390

391

392

393

394

395
Niu L, Tao YB, Chen MS, Fu Q, Dong Y, He H, Xu ZF. 2016. Identification and characterization of tetraploid and octoploid Jatropha curcas induced by colchicine. Caryologia 69:58-66

Niua Y, Luoa H, Suna C, Yangb TJ, Donga L, Huanga L, Chen S. 2014. Expression profiling of the triterpene saponin biosynthesis genes FPS, SS, SE, and DS in the medicinal plant Panax notoginseng. Gene 533:295-303

Omidbaigi R, Mirzaeea M, Hassanib ME, Moghadamc MS. 2010. Induction and identification of polyploidy in basil (Ocimum basilicum L.) medicinal plant by colchicine treatment. International Journal of Plant Production 4:87-98

Pandareesh MD, Anand T, Bhat PV. 2014. Cytoprotective propensity of Bacopa monnieri against hydrogen peroxide induced oxidative damage in neuronal and lung epithelial cells. Cytotechnology 68:157-172

Pfosser M, Amon A, Lelley T, Heberle-Bors E. 1995. Evaluation of sensitivity of flow cytometry in detecting aneuploidy in wheat using disomic and ditelosomic wheat-rye addition lines.

Cytometry Part A 21:387-393

Pour MP, Moieni A, Ebrahimi A, Javidfar F. 2012. Doubled haploid plants following colchicine treatment of microspore-derived embryos of oilseed rape (Brassica napus L.). Plant Cell, Tissue and Organ Culture 108:251-256

Ramasamy S, Chin SP, Sukumaran SD, Buckle MJC, Kiew LV, Chung LY. 2015. In silico and in vitro analysis of bacoside A aglycones and its derivatives as the constituents responsible for the cognitive effects of Bacopa monnieri. PLOS ONE 10:e0126565

Rauf K, Subhan F, Abbas M, Ali SM, Ali G, Ashfaq M, Abbas G. 2014. Inhibitory effect of bacopasides on spontaneous morphine withdrawal induced depression in mice. Phytotherapy Research 28:937-939

Salma U, Kundu S, Hazra AK, Ali MN, Mandal N. 2018. Augmentation of wedelolactone through in vitro tetraploid induction in Eclipta alba (L.) Hassk. Plant Cell, Tissue and Organ Culture 133:289-298

Salma U, Kundu S, Mandal N. 2017. Artificial polyploidy in medicinal plants, Advancement in the last two decades and impending prospects. Journal of Crop Science and Biotechnology 20:919 
396

397

398

399

400

401

402

403

404

405

406

407

408

409

410

411

412

413

414

415

416

417

418

419

420

421

422

423

424

425

426

427

428

429

430

431

432

433

434 Wu YX, Yang FH, Zhao XM, Yang WD. 2011. Identification of tetraploid mutants of

435

Samaddar T, Nath S, Halder M, Sil B, Roychowdhury D, Sen S, Jha S. 2012. Karyotype analysis of three important traditional Indian medicinal plants, Bacopa monnieri, Tylophora indica and Withania somnifera. The Nucleus 55:17-20

Sangeetha N, Ganesh D. 2011. Optimization of protocol for in vitro polyploidization in genetic improvement of Bacopa monnieri L. International Journal of Biological Technology 2:28-34

Sattler MC, Carvalho CR, Clarindo WR. 2016. The polyploidy and its key role in plant breeding. Planta 243:281-296

Sharma P, Yadav S, Srivastava A, Shrivastava N. 2013. Methyl jasmonate mediates upregulation of bacoside A production in shoot cultures of Bacopa monnieri. Biotechnology Letters 35:1211125

Sharma S, Kamal B, Rathi N, Chauhan S, Jadon V, Vats N, Gehlot A, Arya S. 2010. In vitro rapid and mass multiplication of highly valuable medicinal plant Bacopa monnieri (L.) Wettst. African Journal of Biotechnology 9:8318-8322

Tewari DN. 2000. Report of the task force on conservation and sustainable use of medicinal plants. Government of India, Planning Commission, New Delhi

Tripathi N, Chouhan DS, Saini N, Tiwari S. 2012. Assessment of genetic variations among highly endangered medicinal plant Bacopa monnieri (L.) from central India using RAPD and ISSR analysis. 3 Biotech 2:327-336

Uabundit N, Wattanathorn J, Mucimapura S, Ingkaninan K. 2010. Cognitive enhancement and neuroprotective effects of Bacopa monnieri in Alzheimer's disease model. Journal of Ethnopharmacology 127:26-31

Wang LJ, Sheng MY, Wen PC, Du JY. 2017. Morphological, physiological, cytological and phytochemical studies in diploid and colchicine-induced tetraploid plants of Fagopyrum tataricum (L.) Gaertn. Botanical Studies 58:2

Wu L, Zhang D, Xue M, Qian J, He Y, Wang S. 2014. Overexpression of the maize GRF10, an endogenous truncated growth-regulating factor protein, leads to reduction in leaf size and plant height. Journal of Integrative Plant Biology 56:1053-1063

Platycodon grandiflorus by colchicine induction. Caryologia 64:343-349

PeerJ reviewing PDF | (2019:05:37845:2:0:NEW 21 Sep 2019) 
436

437 Yan HJ, Xiong Y, Zhang HY, He ML. 2016. In vitro induction and morphological characteristics 438 of octoploid plants in Pogostemon cablin. Breeding Science 66:169-174

439

440 Zhou K, Fleet P, Nevo E, Zhang X, Sun G. 2017. Transcriptome analysis reveals plant response 441 to colchicine treatment during on chromosome doubling. Scientific Reports 7:8503 


\section{Table $\mathbf{1}$ (on next page)}

Effect of concentration and treatment duration of colchicine on polyploidy induction in nodal segments of Bacopa monnieri.

${ }^{\text {a }}$ Average value represents as mean \pm SE of a number of regenerants per nodal segment, calculated from eight nodal segments at 8 weeks after culture. Different letters within the same column indicate significant differences, analyzed by Duncan's Multiple Range Test (DMRT) at $p \leq 0.01$.

${ }^{\mathrm{b}}$ Percentage value was calculated from number of mixoploid or tetraploid per total number of regenerants in each treatment.

${ }^{\mathrm{c}}$ Data were summarized by all regenerants from colchicine treatment combinations. 
Table 1 Effect of concentration and treatment duration of colchicine on polyploidy induction in nodal segments of Bacopa monnieri.

\begin{tabular}{|c|c|c|c|c|c|c|c|c|}
\hline \multirow{3}{*}{$\begin{array}{l}\text { Time of } \\
\text { treatment (h) }\end{array}$} & \multirow{3}{*}{$\begin{array}{c}\text { Colchicine } \\
(\% \text { w/v) }\end{array}$} & \multirow{2}{*}{\multicolumn{2}{|c|}{ No. of regenerant }} & \multicolumn{5}{|c|}{ Flow cytometry analysis } \\
\hline & & & & \multirow{2}{*}{$\begin{array}{l}\text { No. of tested } \\
\text { regenerants }\end{array}$} & \multicolumn{2}{|c|}{ Mixoploid } & \multicolumn{2}{|c|}{ Tetraploid } \\
\hline & & Total & Average $^{a}$ & & Number & $\%^{\mathrm{b}}$ & Number & $\% \%^{b}$ \\
\hline \multirow{7}{*}{24} & 0 & 97 & $12.1 \pm 3.4 b$ & 27 & 0 & 0 & 0 & 0 \\
\hline & 0.025 & 176 & $22.0 \pm 9.4 \mathrm{a}$ & 25 & 1 & 0.6 & 0 & 0 \\
\hline & 0.05 & 112 & $14.0 \pm 4.4 \mathrm{ab}$ & 29 & 1 & 0.9 & 3 & 2.7 \\
\hline & 0.075 & 149 & $18.6 \pm 5.8 \mathrm{ab}$ & 34 & 2 & 1.3 & 14 & 9.4 \\
\hline & 0.1 & 120 & $15.0 \pm 4.6 \mathrm{ab}$ & 35 & 5 & 4.2 & 9 & 7.5 \\
\hline & 0.5 & 115 & $14.4 \pm 8.8 \mathrm{ab}$ & 33 & 1 & 0.9 & 7 & 6.1 \\
\hline & Total $^{\mathrm{c}}$ & 672 & & 156 & 10 & 1.4 & 33 & 4.9 \\
\hline \multirow{7}{*}{48} & 0 & 81 & $10.1 \pm 5.6 \quad b$ & 26 & 0 & 0 & 0 & 0 \\
\hline & 0.025 & 151 & $18.9 \pm 2.9 \mathrm{ab}$ & 34 & 1 & 0.7 & 2 & 1.3 \\
\hline & 0.05 & 143 & $17.9 \pm 10.5 \mathrm{ab}$ & 35 & 0 & 0 & 15 & 10.5 \\
\hline & 0.075 & 108 & $13.5 \pm 5.0 \mathrm{ab}$ & 33 & 0 & 0 & 11 & 10.2 \\
\hline & 0.1 & 99 & $12.4 \pm 2.9 \quad b$ & 36 & 5 & 5.1 & 10 & 10.1 \\
\hline & 0.5 & 89 & $11.1 \pm 4.5 \quad b$ & 32 & 2 & 2.2 & 13 & 14.6 \\
\hline & Total $^{\mathrm{c}}$ & 590 & & 170 & 8 & 1.4 & 51 & 8.6 \\
\hline Total $^{\mathrm{c}}$ & & 1,262 & & 326 & 18 & 1.4 & 84 & 6.7 \\
\hline
\end{tabular}

2 a Average value represents as mean \pm SE of a number of regenerants per nodal segment, calculated from eight nodal segments at 8

3 weeks after culture. Different letters within the same column indicate significant differences, analyzed by Duncan's Multiple Range

4 Test (DMRT) at $p \leq 0.01$.

$5 \quad \mathrm{~b}$ Percentage value was calculated from number of mixoploid or tetraploid per total number of regenerants in each treatment.

$6 \quad{ }^{\mathrm{c}}$ Data were summarized by all regenerants from colchicine treatment combinations. 


\section{Table 2 (on next page)}

Accumulation of bacoside contents in autotetraploid plants of Bacopa monnieri after growth in $1 / 2 \mathrm{HS}$ for 30 days, analyzed using HPLC technique.

The data represent the mean \pm SE of three biological replicates. Different letters within the same column indicate significant differences analyzed by DMRT at $p \leq 0.05$.

${ }^{a}$ The yield of bacoside was calculated on the basis of dry weight of individual plant. 
1 Table 2 Accumulation of bacoside contents in autotetraploid plants of Bacopa monnieri after growth in $1 / 2 \mathrm{HS}$ for 30 days, analyzed 2 using HPLC technique.

\begin{tabular}{|c|c|c|c|c|c|c|c|c|c|c|}
\hline \multirow{2}{*}{$\begin{array}{c}\text { Clone } \\
\text { no. }\end{array}$} & \multicolumn{5}{|l|}{ Content (\%DW) } & \multicolumn{5}{|c|}{ Yield $\left(m g \text { plant }{ }^{-1}\right)^{\mathrm{a}}$} \\
\hline & Bacoside A & Bacopaside II & Bacopaside X & Bacopasaponin C & Total bacoside & Bacoside A & Bacopaside II & Bacopaside $X$ & Bacopasaponin C & Total bacoside \\
\hline $2 x$ & $0.22 \pm 0.03 \mathrm{ab}$ & $0.66 \pm 0.12 \mathrm{a}-\mathrm{c}$ & $0.17 \pm 0.05 \mathrm{~b}$ & $0.72 \pm 0.12 b c$ & $1.77 \pm 0.31 \mathrm{ab}$ & $0.08 \pm 0.01 \mathrm{~b}-\mathrm{d}$ & $0.25 \pm 0.05 \mathrm{c}-\mathrm{e}$ & $0.06 \pm 0.02 \mathrm{bc}$ & $0.27 \pm 0.05 \mathrm{~b}-\mathrm{d}$ & $0.68 \pm 0.13 \mathrm{~b}-\mathrm{d}$ \\
\hline $4 x-9$ & $0.12 \pm 0.02 \mathrm{c}-\mathrm{g}$ & $0.54 \pm 0.12 b c$ & $0.57 \pm 0.11 \mathrm{a}$ & $0.25 \pm 0.06 \mathrm{~d}-\mathrm{f}$ & $1.48 \pm 0.31 \mathrm{~b}$ & $0.05 \pm 0.01 \mathrm{c}-\mathrm{f}$ & $0.23 \pm 0.05 \mathrm{de}$ & $0.25 \pm 0.04 \mathrm{a}$ & $0.11 \pm 0.02 \mathrm{~d}$ & $0.64 \pm 0.13 \mathrm{~b}-\mathrm{d}$ \\
\hline $4 x-19$ & $0.14 \pm 0.03 \mathrm{~b}-\mathrm{g}$ & $0.67 \pm 0.13 \mathrm{a}-\mathrm{c}$ & $0.00 \pm 0.00 \mathrm{~b}$ & $0.62 \pm 0.13 \mathrm{~b}-\mathrm{e}$ & $1.43 \pm 0.29 \mathrm{~b}$ & $0.06 \pm 0.01 \mathrm{~b}-\mathrm{f}$ & $0.30 \pm 0.06 \mathrm{c}-\mathrm{e}$ & $0.00 \pm 0.00 \mathrm{c}$ & $0.28 \pm 0.06 \mathrm{~b}-\mathrm{d}$ & $0.64 \pm 0.13 \mathrm{~b}-\mathrm{d}$ \\
\hline $4 x-20$ & $0.05 \pm 0.01 \mathrm{~g}$ & $0.33 \pm 0.05 \mathrm{c}$ & $0.37 \pm 0.07 \mathrm{a}$ & $0.27 \pm 0.06 \mathrm{~d}-\mathrm{f}$ & $1.01 \pm 0.19 \mathrm{~b}$ & $0.02 \pm 0.00 \mathrm{f}$ & $0.14 \pm 0.02 \mathrm{e}$ & $0.16 \pm 0.02 \mathrm{ab}$ & $0.11 \pm 0.02 \mathrm{~d}$ & $0.43 \pm 0.07 \mathrm{~d}$ \\
\hline $4 x-23$ & $0.20 \pm 0.02 \mathrm{a}-\mathrm{c}$ & $0.85 \pm 0.14 \mathrm{ab}$ & $0.00 \pm 0.00 \mathrm{~b}$ & $0.84 \pm 0.12 b$ & $1.89 \pm 0.28 \mathrm{ab}$ & $0.11 \pm 0.01 \mathrm{ab}$ & $0.46 \pm 0.05 \mathrm{a}-\mathrm{c}$ & $0.00 \pm 0.00 \mathrm{c}$ & $0.47 \pm 0.03 \mathrm{~b}$ & $1.04 \pm 0.08 \mathrm{bc}$ \\
\hline $4 x-40$ & $0.07 \pm 0.01 \mathrm{e}-\mathrm{g}$ & $0.34 \pm 0.04 \mathrm{c}$ & $0.38 \pm 0.05 \mathrm{a}$ & $0.15 \pm 0.03 \mathrm{f}$ & $0.94 \pm 0.12 b$ & $0.05 \pm 0.01 \mathrm{c}-\mathrm{f}$ & $0.23 \pm 0.05 \mathrm{de}$ & $0.26 \pm 0.05 \mathrm{a}$ & $0.11 \pm 0.03 \mathrm{~d}$ & $0.64 \pm 0.14 \mathrm{~b}-\mathrm{d}$ \\
\hline $4 x-56$ & $0.10 \pm 0.02 \mathrm{~d}-\mathrm{g}$ & $0.48 \pm 0.10 \mathrm{bc}$ & $0.54 \pm 0.11 \mathrm{a}$ & $0.26 \pm 0.05 \mathrm{~d}-\mathrm{f}$ & $1.37 \pm 0.29 \mathrm{~b}$ & $0.04 \pm 0.01 \mathrm{~d}-\mathrm{f}$ & $0.16 \pm 0.04 \mathrm{e}$ & $0.19 \pm 0.04 \mathrm{a}$ & $0.09 \pm 0.02 \mathrm{~d}$ & $0.47 \pm 0.11 \mathrm{~d}$ \\
\hline $4 x-59$ & $0.25 \pm 0.05 \mathrm{a}$ & $1.05 \pm 0.24 \mathrm{a}$ & $0.12 \pm 0.01 \mathrm{~b}$ & $1.30 \pm 0.29 \mathrm{a}$ & $2.73 \pm 0.60 \mathrm{a}$ & $0.15 \pm 0.03 \mathrm{a}$ & $0.60 \pm 0.13 \mathrm{a}$ & $0.07 \pm 0.01 \mathrm{bc}$ & $0.74 \pm 0.15 \mathrm{a}$ & $1.55 \pm 0.31 \mathrm{a}$ \\
\hline $4 x-62$ & $0.17 \pm 0.04 \mathrm{a}-\mathrm{d}$ & $0.75 \pm 0.15 \mathrm{a}-\mathrm{c}$ & $0.00 \pm 0.00 \mathrm{~b}$ & $0.68 \pm 0.16 \mathrm{~b}-\mathrm{d}$ & $1.59 \pm 0.34 \mathrm{~b}$ & $0.09 \pm 0.02 \mathrm{bc}$ & $0.40 \pm 0.07 \mathrm{a}-\mathrm{d}$ & $0.00 \pm 0.00 \mathrm{c}$ & $0.36 \pm 0.07 \mathrm{bc}$ & $0.84 \pm 0.16 \mathrm{~b}-\mathrm{d}$ \\
\hline $4 x-88$ & $0.09 \pm 0.01 \mathrm{~d}-\mathrm{g}$ & $0.40 \pm 0.02 \mathrm{bc}$ & $0.39 \pm 0.02 \mathrm{a}$ & $0.19 \pm 0.02 \mathrm{ef}$ & $1.07 \pm 0.06 \mathrm{~b}$ & $0.05 \pm 0.00 \mathrm{c}-\mathrm{f}$ & $0.19 \pm 0.01 \mathrm{de}$ & $0.19 \pm 0.01 \mathrm{a}$ & $0.09 \pm 0.00 \mathrm{~d}$ & $0.53 \pm 0.02 \mathrm{~cd}$ \\
\hline $4 x-94$ & $0.15 \pm 0.04 \mathrm{~b}-\mathrm{e}$ & $0.77 \pm 0.19 \mathrm{a}-\mathrm{c}$ & $0.00 \pm 0.00 \mathrm{~b}$ & $0.81 \pm 0.22 \mathrm{~b}$ & $1.74 \pm 0.44 \mathrm{ab}$ & $0.07 \pm 0.01 \mathrm{~b}-\mathrm{e}$ & $0.35 \pm 0.08 \mathrm{~b}$-e & $0.00 \pm 0.00 \mathrm{c}$ & $0.37 \pm 0.09 \mathrm{bc}$ & $0.80 \pm 0.19 \mathrm{~b}-\mathrm{d}$ \\
\hline $4 x-98$ & $0.06 \pm 0.02 \mathrm{e}-\mathrm{g}$ & $0.42 \pm 0.12 b c$ & $0.40 \pm 0.12 \mathrm{a}$ & $0.20 \pm 0.06 \mathrm{ef}$ & $1.08 \pm 0.32 \mathrm{~b}$ & $0.04 \pm 0.01 \mathrm{~d}-\mathrm{f}$ & $0.24 \pm 0.07 \mathrm{de}$ & $0.23 \pm 0.07 \mathrm{a}$ & $0.11 \pm 0.04 \mathrm{~d}$ & $0.62 \pm 0.20 \mathrm{~b}-\mathrm{d}$ \\
\hline $4 x-99$ & $0.15 \pm 0.03 \mathrm{~b}-\mathrm{f}$ & $0.70 \pm 0.15 \mathrm{a}-\mathrm{c}$ & $0.00 \pm 0.00 \mathrm{~b}$ & $0.38 \pm 0.09 \mathrm{c}-\mathrm{f}$ & $1.23 \pm 0.27 \mathrm{~b}$ & $0.06 \pm 0.02 \mathrm{c}-\mathrm{f}$ & $0.31 \pm 0.08 \mathrm{c}-\mathrm{e}$ & $0.00 \pm 0.00 \mathrm{c}$ & $0.17 \pm 0.05 \mathrm{~cd}$ & $0.54 \pm 0.14 \mathrm{~cd}$ \\
\hline $4 x-103$ & $0.13 \pm 0.03 \mathrm{~b}-\mathrm{g}$ & $0.68 \pm 0.14 \mathrm{a}-\mathrm{c}$ & $0.00 \pm 0.00 \mathrm{~b}$ & $0.61 \pm 0.14 \mathrm{~b}$-e & $1.42 \pm 0.31 \mathrm{~b}$ & $0.10 \pm 0.02 \mathrm{~b}$ & $0.53 \pm 0.10 \mathrm{ab}$ & $0.00 \pm 0.00 \mathrm{c}$ & $0.47 \pm 0.10 \mathrm{~b}$ & $1.10 \pm 0.22 \mathrm{ab}$ \\
\hline $4 x-115$ & $0.06 \pm 0.03 \mathrm{fg}$ & $0.42 \pm 0.10 \mathrm{bc}$ & $0.53 \pm 0.14 \mathrm{a}$ & $0.38 \pm 0.10 \mathrm{c}-\mathrm{f}$ & $1.39 \pm 0.36 \mathrm{~b}$ & $0.03 \pm 0.01 \mathrm{ef}$ & $0.20 \pm 0.04 \mathrm{de}$ & $0.26 \pm 0.06 \mathrm{a}$ & $0.19 \pm 0.04 \mathrm{~cd}$ & $0.68 \pm 0.16 \mathrm{~b}-\mathrm{d}$ \\
\hline
\end{tabular}

3 The data represent the mean $\pm \mathrm{SE}$ of three biological replicates. Different letters within the same column indicate significant

4 differences analyzed by DMRT at $p \leq 0.05$.

5 a The yield of bacoside was calculated on the basis of dry weight of individual plant.

6 
Figure 1

Effect of concentrations and treatment duration of colchicine on shoot regeneration in Bacopa monnieri at 8 weeks after transferred to $1 / 2 \mathrm{MS}(\mathrm{A})$.

Some morphological variations were observed in regenerated Bacopa monnieri after colchicine treatment such as albino leaf and stems (B), spiral stem (C), variegated leaves (D), whorl of three leaves (E), whorl of four leaves (F), and a fasciated stem (arrow) with two apical shoots $(G)$. Bars indicates $1 \mathrm{~cm}$. 


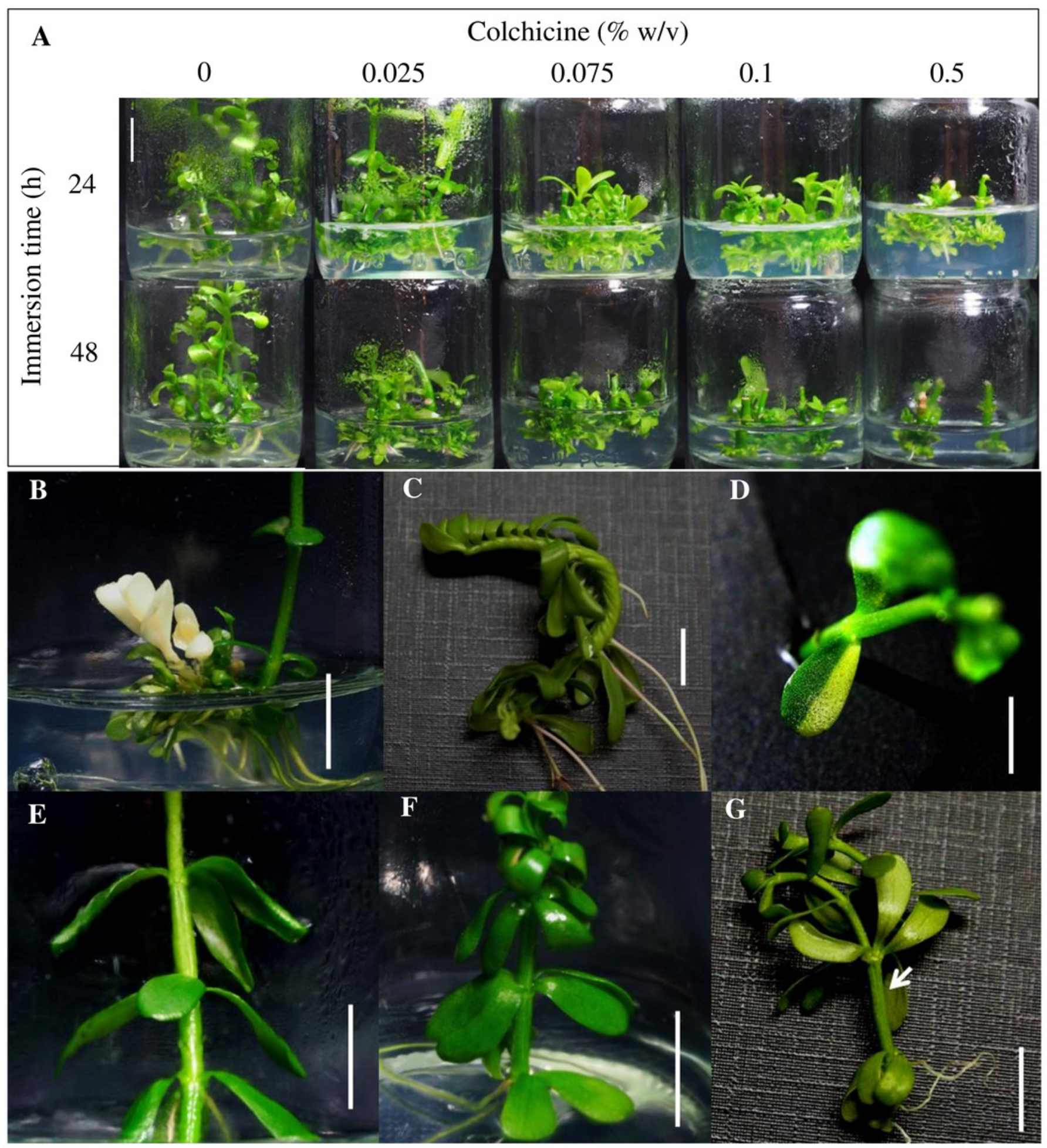


Figure 2

Identification of polyploid Bacopa monnieri using flow cytometry. Histograms of diploid $(A)$, autotetraploid (B) and mixoploid (C) are shown. 

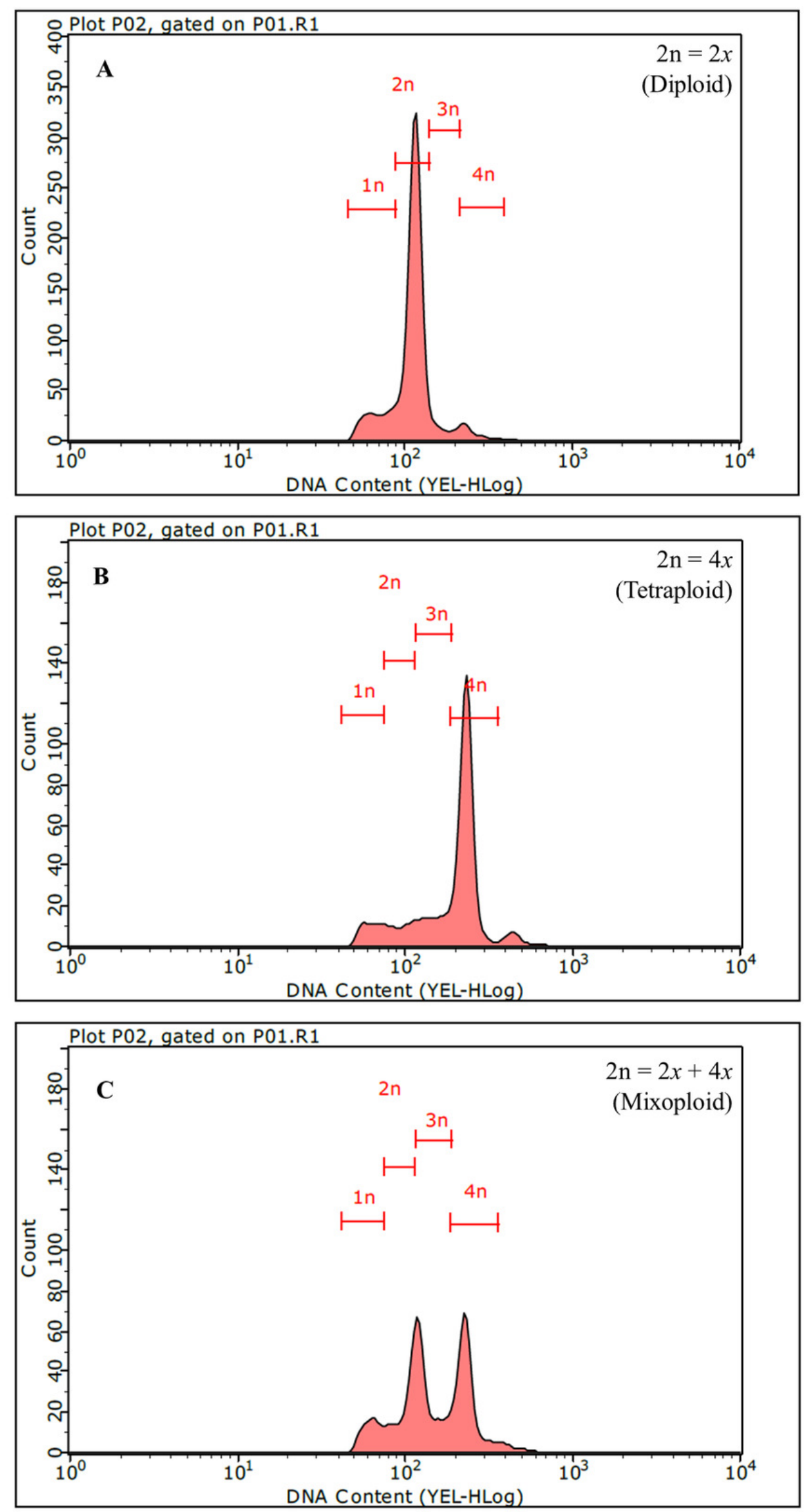

Peer] reviewing PDF | (2019:05:37845:2:0:NEW 21 Sep 2019) 
Figure 3

Fresh weight (A), dry weight (B) and shoot height (C) in selected autotetraploid plants of Bacopa monnieri after growth in $1 / 2 \mathrm{HS}$ for 30 days.

Data are the mean of five plants and the error bar represents SE. The single asterisk $(*)$, and double asterisk $(* *)$ indicate significant difference $(p \leq 0.05)$ and highly significant difference ( $p \leq 0.01$ ) of autotetraploid plants $(4 x)$ compared to diploid plant $(2 x)$ by $t$-test, respectively. 
A

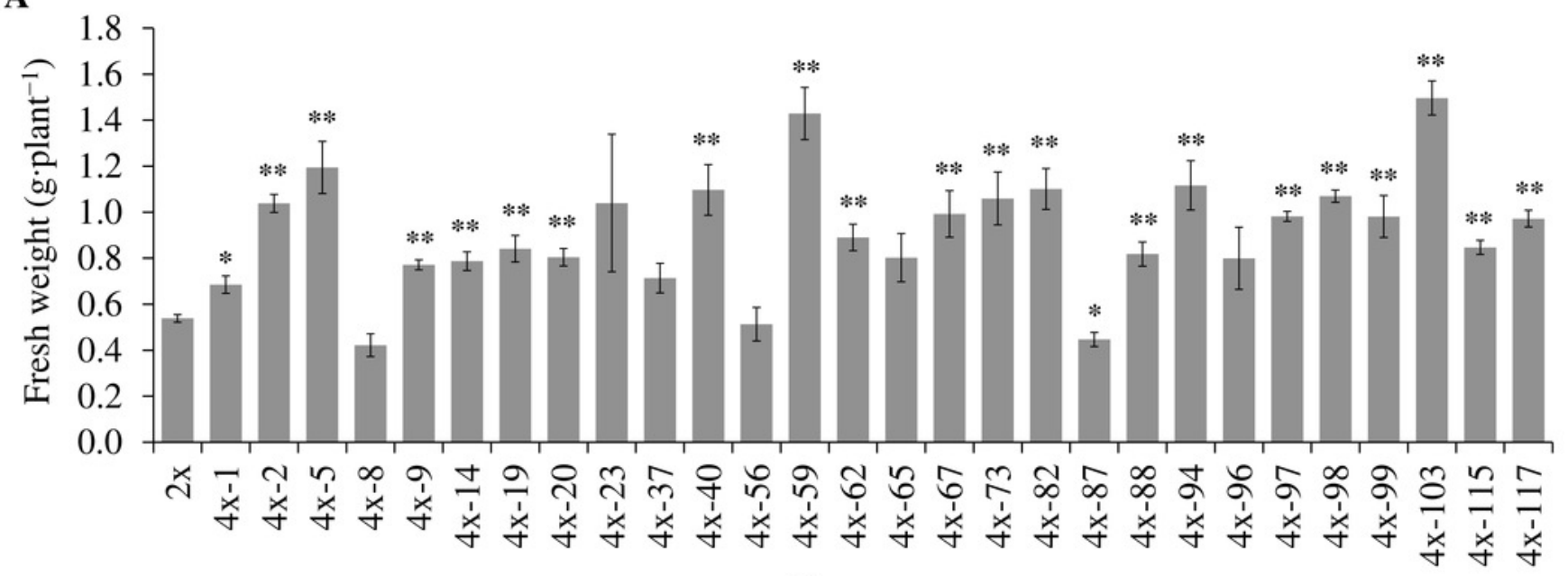

B

Clone no.

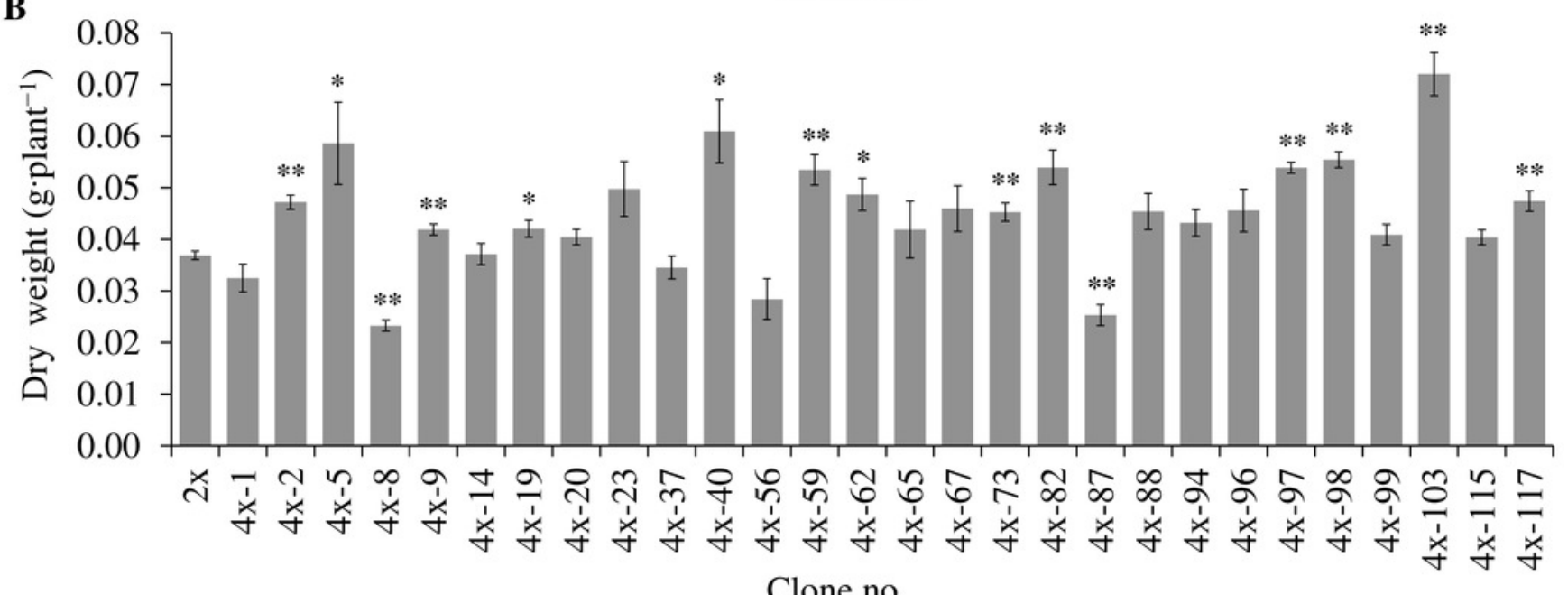

C Clone no.

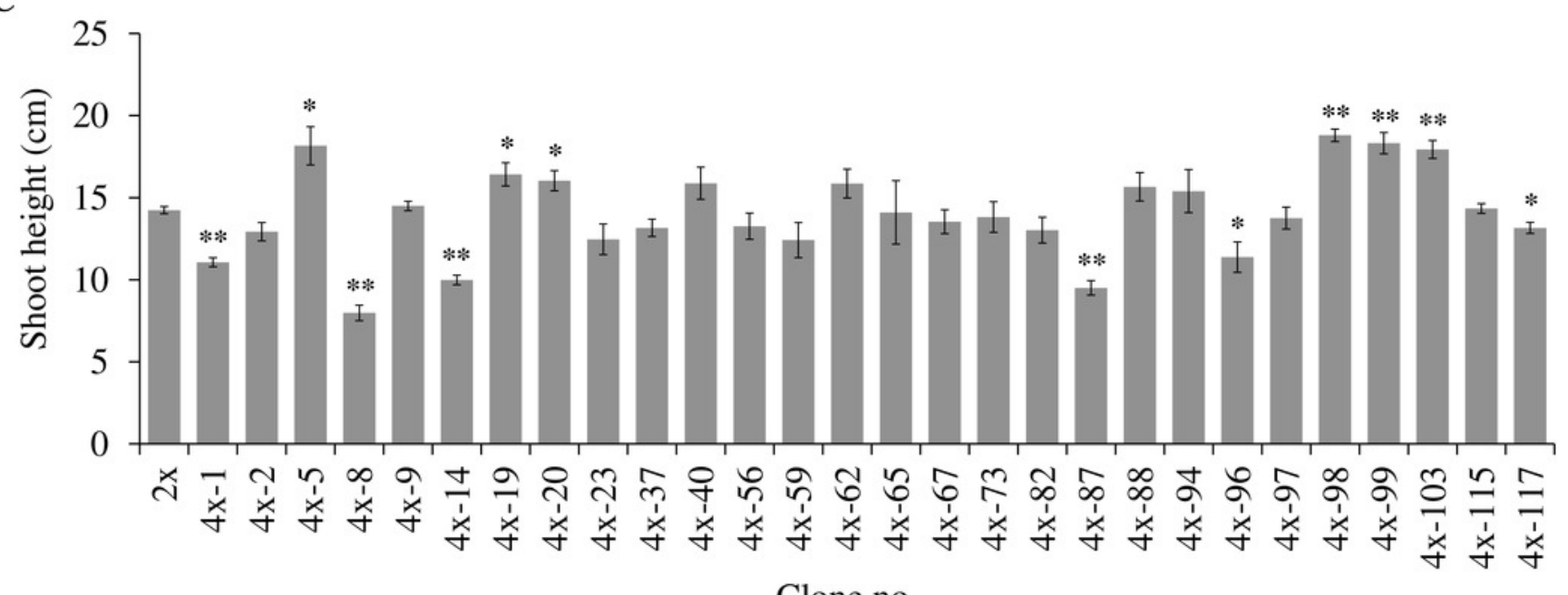

Clone no. 


\section{Figure 4}

Morphological characters in diploid (A) and five representative autotetraploid (B-E) plants of Bacopa monnieri after growth in $1 / 2 \mathrm{HS}$ for 30 days; bar indicates $5 \mathrm{~cm}$.

Cross sections represent leaf thickness ( $\mathrm{F}-\mathrm{G})$ and stem diameter $(\mathrm{H}-\mathrm{I})$ of diploid $(\mathrm{F}$ and $\mathrm{H})$ and one representative sample of tetraploid ( $G$ and I) Bacopa monnieri, bars indicate $250 \mu \mathrm{m}$. Measurement of leaf thickness $(\mathrm{J})$ and stem diameter (K) were undertaken with 5 measuring points per leaf or stem of five individual plants after growth in $1 / 2 \mathrm{HS}$ for 30 days. The different letters above the bars indicate significant difference at $p \leq 0.01$ according to DMRT. 

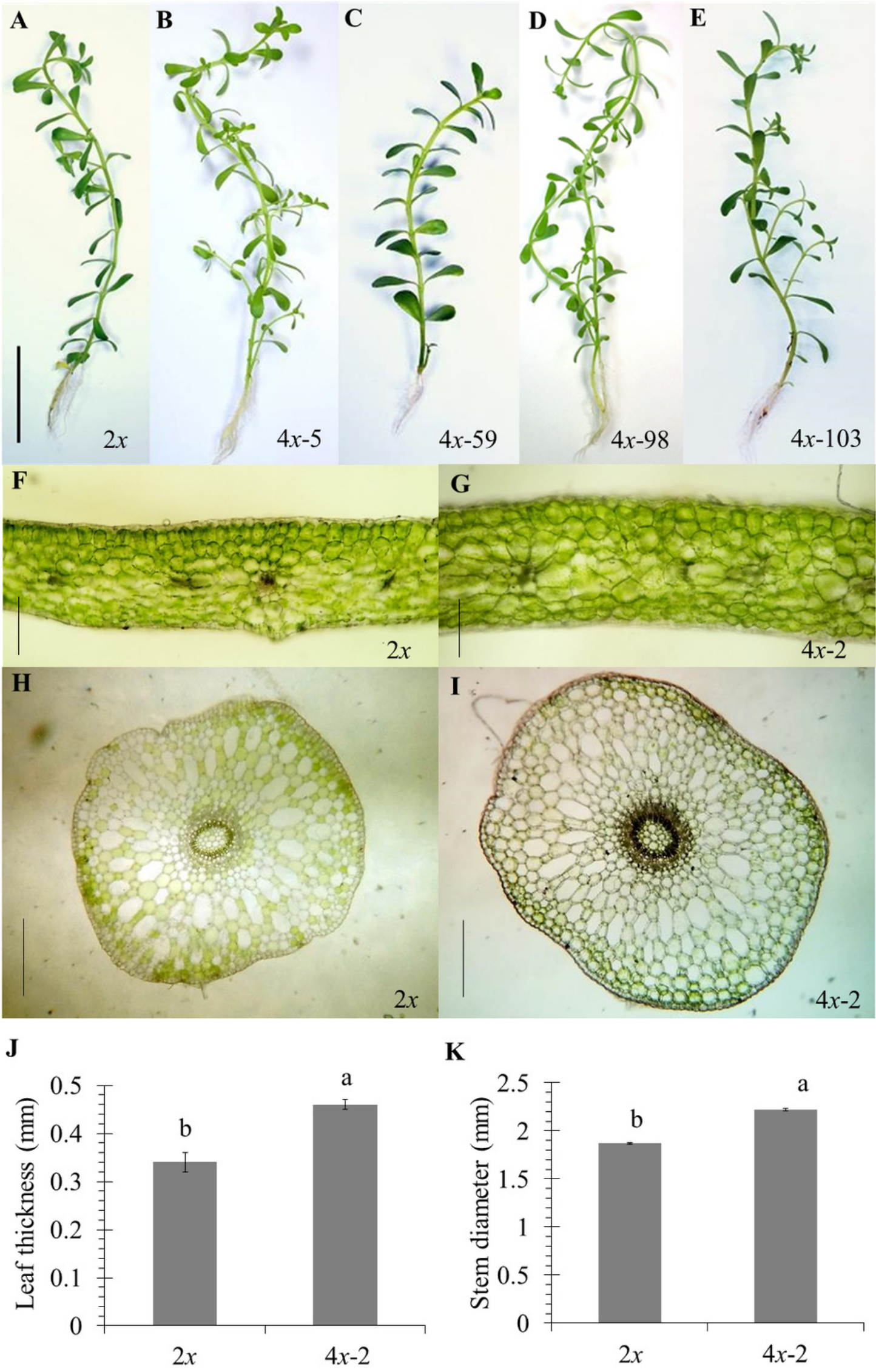